Skin

Appendage

Disorders
Skin Appendage Disord 2016;2:116-119

DOI: 10.1159/000449418
Received: July 12, 2016

Accepted: August 24, 2016

Published online: September 21, 2016

\title{
Periungual Lesion due to Secondary Syphilis
}

\author{
Leandro Noriega $^{\mathrm{a}}$ Nilton Gioia Di Chiacchio ${ }^{\mathrm{a}}$ Flávia Cury Rezende ${ }^{\mathrm{b}}$ \\ Nilton Di Chiacchio ${ }^{a}$ \\ ${ }^{a}$ Dermatology Clinic, Hospital do Servidor Público Municipal de São Paulo, and b Dermatology Clinic, \\ Hospital da Faculdade de Medicina do ABC, São Paulo, Brazil
}

\section{Established Facts}

- In the last few years, an increase in the incidence rate of syphilis has been observed in several countries.

- Syphilis, especially in the secondary form, has different clinical features, affecting different organs, and mimicking many diseases.

\section{Novel Insights}

- We describe a case of periungual secondary syphilis presenting as an erythematous scaly plaque.

\section{Key Words}

Nail disorders $\cdot$ Skin diseases $\cdot$ Syphilis

\begin{abstract}
Several countries experience a new epidemic of syphilis, mainly due to the changes in risk behaviors. Dermatologists play an important role in the diagnosis, since cutaneous manifestations are frequent during disease progression. We report a rare case of secondary syphilis with periungual involvement. Syphilis, especially in the secondary form, may present with different clinical features, affecting different organs, and mimicking many diseases. Although nail apparatus lesions are more common in the primary form of the disease, they may also be present in the secondary and tertiary forms. Therefore, a comprehensive knowledge of the diverse forms of syphilis presentation is important for an early diagnosis and timely treatment.
\end{abstract}

(c) 2016 S. Karger AG, Basel

\section{KARGER}

(C) 2016 S. Karger AG, Basel

2296-9195/16/0024-0116\$39.50/0

E-Mail karger@karger.com

www.karger.com/sad

\section{Introduction}

Syphilis is described as one of the major diseases in the history of mankind, its first outbreak being reported at the end of the 15th century. During that period, typical clinical manifestations were reported, and the mortality rate ranged from 20 to $40 \%$ [1]. The discovery and introduction of penicillin as a form of treatment caused a dramatic reduction of its incidence as well as of morbidity and mortality $[1,2]$. Despite this great advancement, in the last few years, an increase in the incidence rate of the disease has been observed in several countries, associated with a change in risk behaviors, particularly in the group of men who have sex with men [3-5]. In the United States, the annual detection rate of primary and secondary syphilis increased from 2.1 to 5.3 cases per 100,000 inhabitants during 2000 to 2013 [6]. 
Fig. 1. a Erythematous scaly plaque in the lateral region of the left fifth finger extending up to the lateral nail fold and part of the hyponychium. b Partial involvement of the hyponychium and volar region.
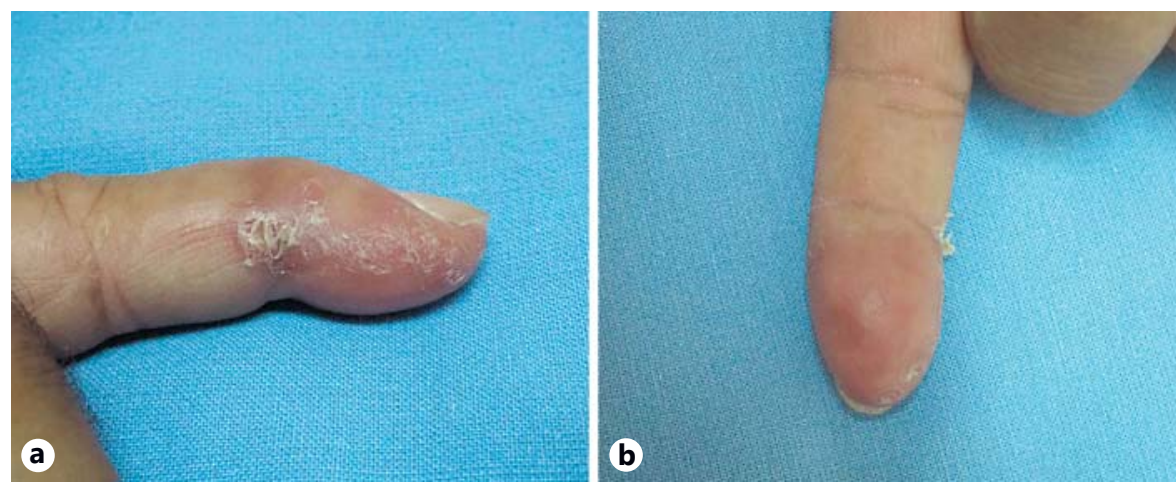

In the acquired form of the disease, Treponema pallidum is primarily sexually transmitted, and the natural history of the disease is characterized by periods of activity (primary, secondary, and tertiary syphilis) and periods of latency (latent syphilis). In addition, syphilis can also be classified as early - when the diagnosis is made within the first 12 months from infection - or late - when it has been present for more than 12 months [2].

The disease is especially important for dermatology due to the wide variety of clinical forms it may assume, so that it is called 'the great simulator' [5]. Although uncommon, the nail unit may be affected in primary, secondary, and tertiary phases [7]. We report a rare case of secondary syphilis with a periungual lesion.

\section{Case Report}

A 52-year-old male patient presented with the complaint of a lesion on the left fifth finger and the left leg for 4 months, with simultaneous onset and progressive growth. He reported discrete pruritus but denied pain, local secretion, triggering factors, or genital lesions. He did not have comorbidities and did not use any medications.

The dermatologic exam showed an erythematous scaly plaque in the lateral region of the left fifth finger extending up to the lateral nail fold and to part of the hyponychium (fig. 1). On the posterior region of the left leg, an erythematous scaly plaque with a pale center was observed (fig. 2).

The clinical hypothesis was dyshidrotic eczema and Bowen's disease for the finger lesion and nummular eczema for the leg lesion. An incisional biopsy was performed in both lesions. The histological examination showed an epidermis with slender and elongated interpapillary crests, segments of vacuolar degeneration of the basal layer, necrotic cells, and exocytosis of lymphocytes. The granular layer was irregular, and the corneal layer showed mild laminar hyperkeratosis partially replaced by parakeratosis. The papillary and reticular dermis had a dense band-like perivascular infiltrate, consisting of epithelioid macrophages, plasma cells, and lymphocytes as well. The infiltrate affected the vascular wall, with focuses of spillage of erythrocytes.

Secondary Syphilis

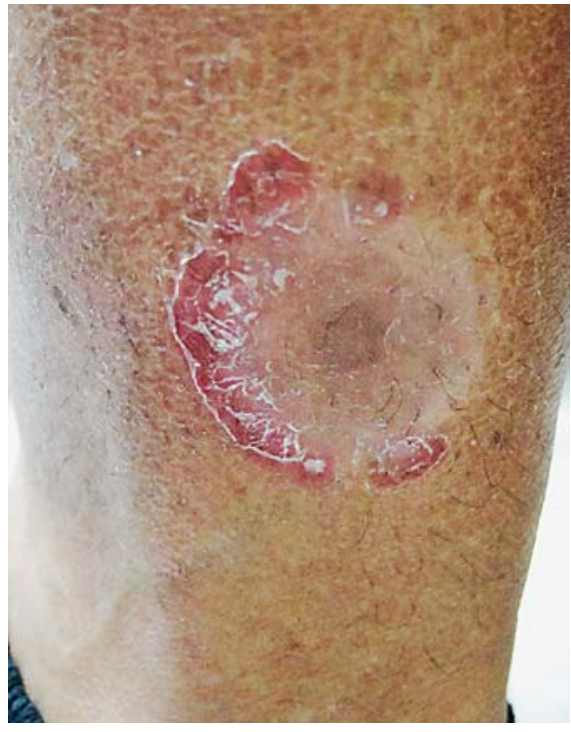

Fig. 2. Posterior region of the left leg with an erythematous scaly plaque. Presence of areas with more active edges and a hypochromic center.

Based on the histological findings, a complementary anamnesis (sexual history) was performed, which revealed an unprotected sexual intercourse 9 months previously. Serologic tests were requested, confirming the diagnosis of syphilis, i.e., positive venereal disease research laboratory (VDRL; 1:256) and positive fluorescent treponemal antibody absorption (FTA-ABS). The clinical features were compatible with the secondary form of the disease. An HIV serologic test was negative, and the liquor analysis was normal (nonreactive VDRL). There were no signs of any other skin lesions or lymphadenopathy.

The treatment employed was 2.4 million units benzathine penicillin $\mathrm{G}$ intramusculary per week for 3 consecutive weeks. The lesion improved 30 days after the first dose (fig. 3 ) and disappeared after 5 months (fig. 4). The nontreponemal test became negative after the same period. No relapse was observed after 24 months. 
Fig. 3. Improvement of the lesions 30 days from the first penicillin $\mathrm{G}$ benzathine dose. a Left fifth finger. b Posterior region of the left leg.

Fig. 4. After 5 months. a Small areas of residual hyperchromia on the left fifth finger. b Posterior region of the left leg with areas of residual hyperchromia and hypochromia.
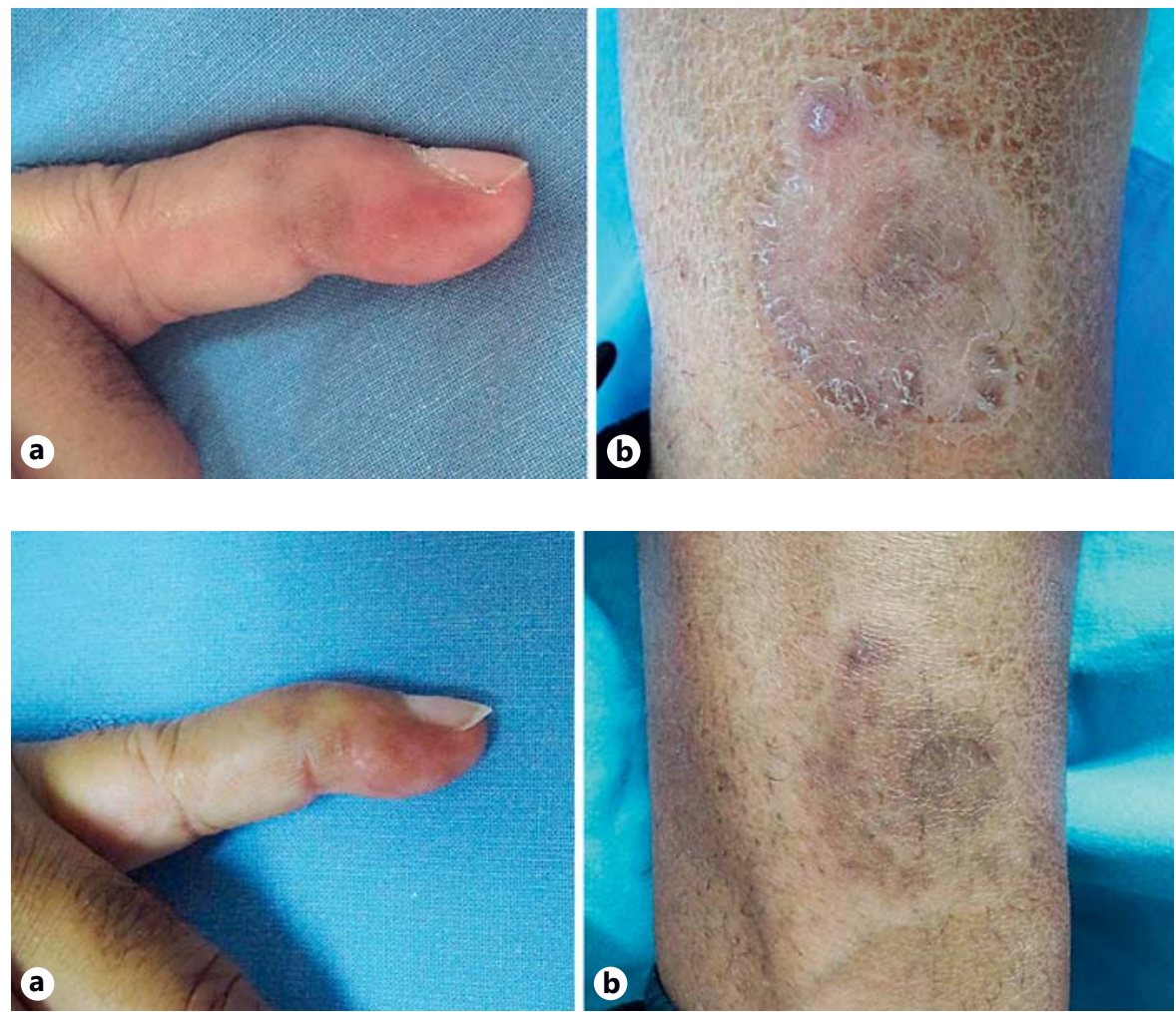

\section{Discussion}

In the primary form of the disease, the specific lesion is the syphilitic chancre, which may be associated with a regional, painless, nonsuppurative lymphadenomegaly $[2,8]$. Extragenital involvement occurs in $2-10 \%$ of cases, with $14 \%$ of them showing a lesion on the finger $[8,9]$. It is usually caused by the contact with genital lesions during sexual practices and rarely occurs in health-care workers due to patient handling $[9,10]$.

During the secondary stage, changes of the nail apparatus may also occur, although rarely [11]. Syphilitic nails can take the following forms: (1) changes of the nail plate, usually due to matrix involvement, and (2) a peri- and/or subungual inflammatory process [7]. The former can progress with brittleness, splitting, fissuring, pitting, onycholysis, elkonyxis, Beau's lines, onychomadesis, and nail loss [7]. The latter is mainly represented by syphilitic paronychia, with a tendency to occur as erythema and edema in the periungual tissues, just as observed in our case. Pain and inflammatory exudate may be present, and occasionally, ulcerative paronychia may occur. Hardly ever anonychia develops $[7,12]$. It may affect one digit, particularly the thumb or the great toe; however, several nails are usually affected [12]. In our case, the periungual lesion was located on the fifth finger only.

Overall, secondary syphilis progresses with outbreaks that spontaneously remit and that are interrupted by increasingly prolonged periods of latency. Approximately $30 \%$ of cases develop the tertiary form, characterized by cutaneous involvement with nodules, ulcerative plaques, tubercles, and/or gummas [2]. Nail involvement is extremely rare in this stage [7].

Due to the broad clinical spectrum, which includes uncommon lesions, it may be difficult to make a diagnosis just through the clinical findings. Often, the diagnosis is confirmed by serological tests, associating a nontreponemal (VDRL) with a treponemal exam (FTA-ABS, hemagglutination, treponemal enzymatic immunoassay, or Western blot). In the secondary stage of the disease, just as observed in our case, serology is the most important diagnostic method [2]. Histopathology is not a routinely employed evaluation for the diagnosis of syphilis, but it can be used in atypical presentations in order to complement the investigation [13].

Therefore, a comprehensive knowledge of the presentation of nail involvement is important for the diagnosis and timely treatment of syphilis. 


\section{Statement of Ethics}

The authors have no ethical conflicts to disclose.

\section{Disclosure Statement}

The authors have no conflicts of interest to declare.

\section{References}

1 Baughn RE, Musher DM: Secondary syphilitic lesions. Clin Microbiol Rev 2005; 18:205216.

2 Avelleira JCR, Bottino G: Syphilis: diagnosis, treatment and control. An Bras Dermatol 2006;81:111-126.

3 Zetola NM, Klausner JD: Syphilis and HIV infection: an update. Clin Infect Dis 2007;44: 1222-1228.

4 Furlan FC, Oliveira AP, Yoshioka MC, Enokihara MM, Michalany NS, Porro AM: Leukocytoclastic vasculitis: another condition that mimics syphilis. An Bras Dermatol 2010;85: 676-679.
5 Bissessor M, Chen M: Syphilis, the great mimicker, is back. Aust Fam Physician 2009;38: 384-387.

6 Patton ME, Su JR, Nelson R, Weinstock H: Primary and secondary syphilis - United States, 2005-2013. Morb Mortal Wkly Rep 2014;63:402-406.

7 Hay RJ, Baran R: Fungal (onychomycosis) and other infections involving the nail apparatus; in Baran R, Dawber RPR, de Berker DAR, et al (eds): Nail Diseases and Their Management. 4 ed. Oxford, Blackwell Scientific, 2012, pp 242-244

8 Ramoni S, Cusini M, Boneschi V, Galloni C, Marchetti S: Primary syphilis of the finger. Sex Transm Dis 2010;37:468.
9 Starzycki Z: Primary syphilis of the fingers. $\mathrm{Br}$ J Vener Dis 1983;59:169-171.

10 Kompanje EJ: Primary syphilitic chancres on arms, fingers and hands: more common than reported. Int J STD AIDS 2013;24:505.

11 Oh IY, Kim H, Park KY, Li K, Kim BJ, Seo SJ, Kim MN, Hong CK: A case of syphilis with nail dystrophy. Korean J Dermatol 2012;50: 628-631.

12 Kingsbury DH, Chester EC Jr, Jansen GT: Syphilitic paronychia: an unusual complaint. Arch Dermatol 1972;105:458.

13 Streit E, Hartschuh W, Flux K: Solitary lesion on finger. Primary syphilitic lesion on finger. Acta Derm Venereol 2013;93:251-252. 